\title{
Short term acupressure therapy on weight-reduction in adolescence: A randomized controlled trial
}

\author{
Ching-Hsiu Hsieh ${ }^{1 *}$, Pei-Ying Chuang ${ }^{2}$, Li-Huan Chen $^{3}$, Han-Wen Wang ${ }^{4}$ \\ ${ }^{1}$ Department of Nursing, Chang Gung University of Science and Technology, Chia-Yi, Taiwan \\ ${ }^{*}$ Corresponding Author: chinghsiuh@yahoo.com \\ ${ }^{2}$ School of Nursing, University of Texas Health Science Center at Houston, Houston, USA \\ ${ }^{3}$ Department of Nursing, Yuanpei University, HsinChu, Taiwan \\ ${ }^{4}$ Department of Emergency Medicine, St. Martin De Porres Hospital, Chia-Yi, Taiwan
}

Received 9 May 2013; revised 9 June 2013; accepted 10 July 2013

Copyright (C) 2013 Ching-Hsiu Hsieh et al. This is an open access article distributed under the Creative Commons Attribution License, which permits unrestricted use, distribution, and reproduction in any medium, provided the original work is properly cited.

\begin{abstract}
Aim: Common treatment options for obesity include a reduced-calorie diet, increased physical activity, behavioral modification, pharmacotherapy, and surgery. Ear acupressure may also be an effective adjunct therapy. Methods: This study used a randomized controlled design to test the effectiveness of auricular acupressure for weight reduction in young, Taiwanese adults with a BMI $\geq 23 \mathrm{~kg} / \mathrm{m}^{2}$. Sixty-eight participants aged 18 to 20 years were recruited from Taiwanese universities at the beginning of the study. After four weeks of auricular therapy, the total sample included 57 young adults. All participants met one time per week for ten minutes. The treatment group received ear acupressure treatment with Semen Vaccariae sticks on auricular acupoints while the control group had adhesive tape placed on ear acupoints, change in BMI from baseline to trial completion. Results: $B M I$ in controls increased significantly by $+0.0133 \mathrm{~kg} / \mathrm{m}^{2}(P=0.000)$ while the intervention group BMI decreased significantly by -0.8022 $\mathrm{kg} / \mathrm{m}^{2}(P \leq 0.0001)$. Conclusions: Just four weeks of auricular acupressure by Semen Vaccariae, sticks may significantly help to decrease BMI among young adults.
\end{abstract}

Keywords: Aurpressure Therapy;

Weight-Reduction; Auricular Acupoint; Randomized Controlled Trial; BMI

\section{INTRODUCTION}

A 2004 study from the United States Department of
Health and Human Services demonstrated that overweight adolescents have a 70 percent chance of becoming overweight or obese adults [1]. If one or more parents are overweight or obese, the risks of becoming overweight or obese in adulthood increase to 80 percent [2] (Centers for Disease Control and Prevention, 2002). To prevent adult obesity, strategies should target young adults. At least, one study has shown that prevention strategies should logically focus on specific ethnic groups which are at the highest risk of becoming obese by the midthirty age range adults [3]. This same study outlines the importance of the development of nursing education in health care and determines that adolescent weight gain could be reduced by ear acupressure.

\section{LITERATURE REVIEW}

Obesity is a frequent, global health risk and remains a major critical public health problem in industrialized countries [4]. Overweight and obesity are associated with numerous chronic health problems, including hypertension, dyslipidemia, insulin resistance and hyperinsulinemia, the metabolic syndrome, diabetes mellitus, gallbladder disease, osteoarthritis, many types of cancer, and increased mortality rates [3-6]. In addition, the prevalence of social and emotional problems among obese adolescents is high, and these social problems are strongly predictive of both short- and long-term psychological outcomes [7].

Overweight and obese individuals are identified according to the classification adopted by the World Health Organization (WHO). Body mass index (BMI; weight in kilograms/height in meters ${ }^{2}$ ) is widely used among adults as a measure of adiposity, with a BMI $\geq 25 \mathrm{~kg} / \mathrm{m}^{2}$ being indicative of overweight and a BMI $\geq 30 \mathrm{~kg} / \mathrm{m}^{2}$ indicating obesity $[1,8]$. However, the WHO consultation on 
BMI in Asian populations, which met in Singapore in 2002, focused exclusively on issues related to overweight and obesity in this cohort. WHO suggested Asian populations use the classification of BMI $\geq 23 \mathrm{~kg} / \mathrm{m}^{2}$ for overweight and BMI $\geq 27.5 \mathrm{~kg} / \mathrm{m}^{2}$ for obesity [8,9]. In the present study, we use the Asian definition for overweight and obesity as BMI $\geq 23 \mathrm{~kg} / \mathrm{m}^{2}$ and $\geq 27 \mathrm{~kg} / \mathrm{m}^{2}$, respectively, to conform to $\mathrm{WHO}$ criteria.

In traditional Chinese medicine (TCM), "Qi" is thought to circulate energy throughout the body. Traditional acupuncturists activate the body through the insertion of needles in to specific areas (acupoints) of the body [10-13]. Practitioners of Chinese medicine believe that an "excess" or "deficiency" of Qi can be normalized by the specific stimulation of selected acupoints [10-15].

One of the tenets of TCM practitioners is that acupuncture treatment may modify central nervous system neurotransmitter levels by stimulating acupoints [10-11]. Auricular acupuncture or acupressure therapy has been used as an adjunctive therapeutic modality in complementary medicine fields worldwide [5,12-16]. The points in the human body where acupuncture or acupressure can be applied are the channels through which spirit passes and are, thus, the defined acupuncture sites. In TCM, the veins and arteries of the ear are believed to connect the internal organs of the entire human body $[6,17]$.

Auricular acupuncture therapy is the method most frequently used for the treatment of obesity [18]. A large body of research shows that the most effective acupuncture points for treating obesity are Shenmen, Mouth, Stomach, Endocrine points, and Small intestine. Stimulating Shenmen point can help participants to become calmer and induce a degree of sedation. Stimulating the auricular mouth acupoint can reduce feelings of anger and has been used to treat oral ulcers. The stomach and endocrine auricular points can diminish appetite and eliminate the sensation of hunger (bringing about feelings of satiety and fullness), thus, achieve effective weight loss [4,6,17,19-22]. The small intestine point can treat dyspepsia and may thereby contribute to the ability to decrease weight [14].

\section{MATERIALS AND METHODS}

\subsection{Demographics and Study Design}

The goal of this study was to compare the efficacy of ear acupressure by Semen Vaccariae (small stick only) on auricular acupoints for the management of overweight and obesity. This study used a randomized controlled design to test the effects of auricular acupressure interventions for weight reduction in young adults with a $\mathrm{BMI} \geq 23 \mathrm{~kg} / \mathrm{m}^{2}$. The total intervention duration was four weeks. The sample consisted of 68 participants who ranged in age from 18 to 20 years old and who were re- cruited from universities in North Taiwan. Ethical approval was obtained from the instruction and informed consent was obtained from each participant. All participants were free to withdraw from the study at any time. Potential benefits of the study include a reduction in a participant's BMI which has potential to improve health status and overall well-being.

\subsection{Intervention}

The subjects selected were thereafter randomly placed into one of two groups. BMI of each participant was determined. For the purpose of this study, a BMI $\geq 23$ $\mathrm{kg} / \mathrm{m}^{2}$ was used to define overweight and $\geq 27 \mathrm{~kg} / \mathrm{m}^{2}$ indicated obesity, conforming to WHO criteria. Both groups received health education describing an appropriate reduced calorie diet and lifestyle modification, such as how to increase activity levels. The control group had adhesive tape placed on the ear acupoints. The experimental group received Semen Vaccariae for acupressure on the auricular acupoints. The points for treating obesity on the ear are Shenmen, Mouth, Stomach, Endocrine, and Small intestine. All participants met one time per week for ten minutes for a total of four weeks. BMI was recorded for each participant each week.

\section{STATISTICS}

B data were analyzed using the SPSS General linear mix-effect model (GLMM) guided variables inferences at individual levels as was appropriate for continuous outcomes. Estimates of the dependent variable, BMI, were evaluated for each group at each weekly meeting and were also assessed for significance. Results were considered to be significant at a $P<0.05$.

\section{RESULTS}

After four weeks of auricular therapy, 11 participants had withdrawn from the study for a variety of reasons. Therefore, these 11 subjects are not included in the final analysis. Final analysis includes 28 subjects in the control group and 29 subjects in the treatment group. The study demographics showed that female students made up 91.22 percent of the sample and male students made up 8.77 percent of final results sample. Table 1 displays

Table 1. Final Demographics by Gender for the Two Group ( $N$ $=57)$.

\begin{tabular}{cccc}
\hline Group & Subjects & $\begin{array}{c}\text { Female students } \\
\text { Frequency (\%) }\end{array}$ & $\begin{array}{c}\text { Male students } \\
\text { Frequency (\%) }\end{array}$ \\
\hline Control group & 28 & $26(45.61 \%)$ & $2(3.50 \%)$ \\
Experimental group & 29 & $26(45.61 \%)$ & $3(5.26 \%)$ \\
Total & 57 & $52(91.22 \%)$ & $5(8.77 \%)$ \\
\hline
\end{tabular}


participant demographics by gender for the two groups.

During the four-week program duration, BMI was measured weekly. After four weeks, BMI of the control group increased significantly by $+0.0457 \mathrm{~kg} / \mathrm{m}^{2}(P=$ $0.000)$. Thus, simply applying adhesive tape to ear acupoints could not decrease BMI after four weeks (Table 2).

After four-week of continuous treatment, the BMI of the treatment group decreased significantly by -0.8022 $\mathrm{kg} / \mathrm{m}^{2}(P \leq 0.0001)$. Participants who received continuous ear acupressure treatment with Semen Vaccariae were noted to have decreased BMI from week to week. Semen Vaccariae ear acupressure worked sufficiently for BMI reduction (Table 2).

\section{DISCUSSION}

The present study results demonstrate that, after 4 weeks of ear acupressure treatment by Semen Vaccariae, participants' BMI decreased significantly by an average of $-0.8022 \mathrm{~kg} / \mathrm{m}^{2}(P \leq 0.0001)$. This result showed that continuous auricular acupressure can decrease BMI, which has been supported by many research studies. For example, Richards and Marley assessed the efficacy of ear acupuncture treatment on weight loss in a 4-week study. Their results showed an average weight loss of 4.0 $\pm 1.4 \mathrm{~kg}(P<0.05)$ in treatment group [17]. Additionally, Soong studied 21 obese patients using various auricular acupressure points for treatment periods ranging from 2 6 weeks and reported a mean weight loss of $3.3 \pm 1.9 \mathrm{~kg}$ with a range of $1-7.3 \mathrm{~kg}$ [14].

\section{CONCLUSIONS}

Reduction of individual body weight and decreasing the prevalence of obesity are critical health issues [23]. The sample size of our study is similar to that in many previous research studies, which reached similar conclusions. However, participants were not representative of both genders. Thus, one limitation is the female pre-

Table 2. Mean difference of BMI $\left(\mathrm{kg} / \mathrm{m}^{2}\right)$ from baseline to the completion of the intervention $(N=57)$.

\begin{tabular}{|c|c|c|c|c|c|c|}
\hline \multirow[t]{2}{*}{ Week } & $\begin{array}{l}\text { Control } \\
\text { Group }\end{array}$ & $t$ & Sig. & $\begin{array}{l}\text { Experimental } \\
\text { Group }\end{array}$ & $t$ & Sig. \\
\hline & BMI Me & ean Diffe & erence & BMI Mea & an Differe & ence \\
\hline $\begin{array}{c}\text { Baseline-1st } \\
\text { Week }\end{array}$ & +0.0190 & -11.702 & 0.000 & -0.2107 & $\begin{array}{c}P \leq \\
0.0001\end{array}$ & $\begin{array}{c}P \leq \\
0.0001\end{array}$ \\
\hline $\begin{array}{l}\text { Baseline-2nd } \\
\text { Week }\end{array}$ & +0.0031 & -8.260 & 0.000 & -0.5187 & $\begin{array}{c}P \leq \\
0.0001\end{array}$ & $\begin{array}{c}P \leq \\
0.0001\end{array}$ \\
\hline $\begin{array}{c}\text { Baseline-3rd } \\
\text { Week }\end{array}$ & +0.0055 & -6.770 & 0.000 & -0.6860 & $\begin{array}{c}P \leq \\
0.0001\end{array}$ & $\begin{array}{c}P \leq \\
0.0001\end{array}$ \\
\hline $\begin{array}{c}\text { Baseline-4th } \\
\text { Week }\end{array}$ & +0.0133 & -7.561 & 0.000 & -0.8022 & $\begin{array}{c}P \leq \\
0.0001\end{array}$ & $\begin{array}{c}P \leq \\
0.0001\end{array}$ \\
\hline
\end{tabular}

dominance in our study and any future studies should involve large groups of subjects and specifically recruit male participants to make our findings generalizable.

According to this study, auricular acupressure by Semen Vaccariae can decrease BMI after just four weeks of treatment. However, long-term treatment and follow-up after treatment are necessary for future studies. Additional research is also needed to show whether the effects observed with auricular acupressure treatment could be sustained after completion of the auricular acupressure treatment program.

\section{REFERENCES}

[1] National Center for Health Statistics. (2004) Prevalence of overweight among children and adolescents: United States, 1999-2000. 28 July 2004.

http://www.cdc.gov/nchs/products/pubs/pubd/hestats/over weight99.htm

[2] National Health and Nutrition Examination Survey (NHANES) 1999-2000. (2002) Hyattsville, MD, US Department of Health and Human Services, Centers for Disease Control and Prevention, National Center for Health Statistics.

[3] National Center for Chronic Disease Prevention and Health Promotion. (2004) Defining overweight and obesity. 28 July 2004. http://www.cdc.gov/nccdphp/dnpa/obesity/defining.htm

[4] Ginsberg-Fellner, F., JagenforfL. L.A. and Carmel, H. (1981) Overweight and obesity in preschool children in New York City. American Journal Clinical Nursing, 34, 2236-2241.

[5] Lei, Z.P. (1998) Treatment of 42 cases of obesity with acupuncture. Journal of Traditional Chinese Medicine, $\mathbf{8}$, 125-126.

[6] Lin, J.G., Lin, J.C. and Sa, L.S. (1994) The effect of an ear acupuncture treatment on lactate after exercise. Journal of China Medical University, 3, 63-67.

[7] Janseen, I., Craig, W.M., Boyce, W.F. and Pickett, W. (2004) Associations between overweight and obesity with bullying behaviors in school-aged children. Pediatrics, 113, 1187-1194. doi:10.1542/peds.113.5.1187

[8] WHO Expert Consultation. (2004) Appropriate bodymass index for Asian populations and its implications for policy and intervention strategies. The Lancet, 363, 157-163. doi:10.1016/S0140-6736(03)15268-3

[9] WHO Expert Committee. (1998) Physical status: The use and interpretation of anthropometry. WHO, Geneva.

[10] Oleson, T. (1996) Auriculotherapy manual: Chinese and Western systems of ear acupuncture. Health care Alternatives, Los Angeles.

[11] Oleson, T. (1998) Differential application of auricular acupuncture for myofascial, autonomic, and naturopathic pain. Medical Acupuncture, 9, 23-28.

[12] Oleson, T. (2002) Auriculotherapy stimulation for neurorehabilitation. NeuroRehabilitation, 17, 49-62.

[13] Vickers, A. and Zollman, C. (1999) ABC of complemen- 
tary medicine: Acupuncture. BMJ, 319, 973-976. doi: $10.1136 / \mathrm{bmj} .319 .7215 .973$

[14] Oleson, T. and Kroening, R. (1983) A comparison of Chinese and Nogier auricular acupuncture points. American Journal of Acupuncture, 11, 205-223.

[15] Mitchell, E.R. (1995) Fighting drug abuse with acupuncture: Thru treatment that works. Pacific View Press, Berkeley.

[16] Frank, B.L. and Soliman, N. (2001) Obesity treatment through auricular therapy and auricular medicine. Medical Acupuncture: A Journal for Physicians Physician, 14, Article 3.

[17] Soong, Y.S. (1975) The treatment of exogenous obesity employing auricular acupuncture. American Journal of Chinese Medicine, 3, 285-287. doi:10.1142/S0192415X75000311

[18] Stux, G. and Pomeranz, B. (1998) Basics of acupuncture, 4th ed. Springer-Verlag, Berlin.

[19] Mazzoni, R., Mannucci, E., Rizzllo, S.M., Ricca, V. and Rotella, C.M. (1999) Failure of acupuncture in the treat- ment of obesity: A pilot study. Eat Weight Disorder, 4 , 198-202.

[20] Richards, D. and Marley, J. (1998) Stimulation of auricular acupuncture points in weight loss. Australia Family Physician, 27, 73-77.

[21] Shafshak, T.S. (1995). Electroacupuncture and exercise in body weight reduction and their application in rehabilitating patients with knee osteoarthritis. The American Journal of Chinese Medicine, 23, 15-25. doi:10.1142/S0192415X95000043

[22] Steiner, R.P., Kupper, N., and Davis, A.W. (1983) Obesity and appetite control: Comparison of acupuncture therapies and behavior modification. Proceedings: International Forum on Family Medicine Education, Society of Teachers of Family Medicine, Kansas City, 313-326.

[23] Ripp, J.M. and Hess, S. (1998) The role of physical activity in the prevention and management of obesity. Journal of the American Dietetic Association, 98, 31-38. doi:10.1016/S0002-8223(98)00708-1 